\title{
Survey of the Initial Employment of Students in Medical Vocational Colleges in China (Yancheng Medicine College)
}

\author{
Qiu Fan * \\ Department of Pharmacy \\ Yancheng Medicine College \\ Yancheng, China \\ E-mail: echo_qf@163.com \\ * Corresponding Author \\ Chen Jun \\ Department of Student Management \\ Yancheng Medicine College \\ Yancheng, China \\ E-mail: 199293@ycmc.edu.cn
}

\author{
Ma Fei \\ Department of Student Management \\ Yancheng Teachers College \\ Yancheng, China \\ E-mail: 110553556@qq.com \\ Liu Hui \\ Department of Pharmacy \\ Yancheng Medicine College \\ Yancheng, China \\ E-mail: liuhui03110@ycmc.edu.cn
}

\begin{abstract}
Objective: To evaluate employment ability of the graduates and improve the quality of training in our college. Method: According to requirements of pharmaceutical industry for the graduates, we formulate training quality assessment plan which contain questionnaire design, questionnaire survey, data sorting, data analysis, and then we find out problems, put forward countermeasures.

Results: The employment competitiveness index ranged from $82.3 \%$ to $99.3 \%$, the average employment status of satisfaction is $42 \% .92 \%$ graduates who took the job relative with the major they learnt in college. The main reason for the graduates who didn't choose major-relative job was the limited recruitment. $33 \%$ graduates think they need more expert practice.

Conclusion: The overall employment rate is high, but the employment quality need to be further improved. The students need more time to practice professional skills. Teachers should pay more attention to attract the interest of students in class and update teaching content.
\end{abstract}

Keywords-Vocational School; Vocational Education; Teaching Assessment; Graduates Survey; Medical College

\section{INTRODUCTION}

In all education systems, vocational education is the most direct and closely related to the national economic construction. It is the base of cultivating the professional technical talents for the country's economic construction [1]. For the development of China's health industry, the cultivation of medical and health personnel in higher vocational education is an indispensable and irreplaceable important mission [2]. In the present stage of economic and social development, facing more challenge of multiple health problems, the task of health work is more arduous [3]. Because China is in the process of industrialization and urbanization, the rapid development of population aging process, the health problems are becoming more complex [4]. In order to adapt to the current situation, more effort are needed to improve the quality of medical vocational and technical education.

The aim of medical vocational colleges is to cultivate the application oriented talents who have enough theoretical knowledge and are able to solve problems in work practice [5]. In order to evaluate the personnel training quality, understand the social evaluation of the students' employment ability, discover the problems in the training process, we designed questionnaire, sorted messages and analyzed data collected in this study.

\section{METHOD}

The subjects of the survey were the students who have been graduated for six months. At this time, the employment situation of graduates tends to be stable, and the graduates who have work experience can also evaluate the level of their knowledge and ability. About eighty percent of the class of 2014 responded to the survey. Totally, 863 questionnaires were distributed, 690 valid questionnaires were collected, and the effective recovery rate was $80 \%$. The total answer rate is $44.75 \%$, covered 12 majors in Yancheng Medicine College. The collected data from questionnaire were record and analyzed using SPSS statistical package program (17.0), and the data of national vocational colleges were supported by MyCOS Group.

The ratio of the employment rate in a major and the highest employment rate in all majors reflects the relative level of employment rate of a major. In the same way, we calculated the ratio of monthly income, the ratio of basic work ability and the ratio of employment status. The specific calculation of employment competitiveness index of a major is the average of the four ratio mentioned, and the maximum average value is $100 \%$.

Basic work ability and job satisfaction data was collected by asking graduate how satisfied to meet the job 
TABLE I. EMPLOYMENT COMPETITIVENESS RANKING OF MAJORS IN YANCHENG MEDICINE COLLEGE

\begin{tabular}{lccccc}
\hline Major & $\begin{array}{c}\text { Employment } \\
\text { competitiveness index }(\%)\end{array}$ & $\begin{array}{c}\text { Employment } \\
\text { rate }(\%)\end{array}$ & $\begin{array}{c}\text { Average monthly } \\
\text { income }(¥)\end{array}$ & $\begin{array}{c}\text { Working } \\
\text { ability }(\%)\end{array}$ & $\begin{array}{c}\text { Job satisfaction } \\
(\%)\end{array}$ \\
\hline $\begin{array}{l}\text { Nursing (Midwifery) } \\
\text { Rehabilitation treatment }\end{array}$ & 99.3 & 100 & 2397 & 55 & 59 \\
technology & 92.1 & 98 & 2403 & 56 & 42 \\
Medical imaging technology & 90.8 & 95 & 2359 & 54 & 44 \\
Nursing (Foreign Nursing) & 90.6 & 99 & 2410 & 52 & 42 \\
Nursing & 90.1 & 98 & 2424 & 51 & 42 \\
Pharmaceutical Technique & 88.7 & 100 & 2342 & 45 & 46 \\
radiation therapy technology & 86.8 & 93 & 2217 & 56 & 37 \\
Pharmacy & 82.3 & 96 & 2093 & 48 & 36 \\
\hline
\end{tabular}

requirements with their work ability and how satisfied they were with their job in the questionnaire. Completely satisfied is $100 \%$. The graduate may be employed full-time job, part-time job or self- employment.

\section{RESULTS}

\section{A. Distribution of the Graduates}

Ninety point five percent of the graduates in our college were fully employment; three percent of the graduate took part-time job; one point eight percent of them were self-employment; two percent were in graduate school; one point six percent of them keep looking for job. The results were presented in Figure 1, the blue column were data of our college, compared with the level of the national vocational colleges, the percentage of employment were a little lower.

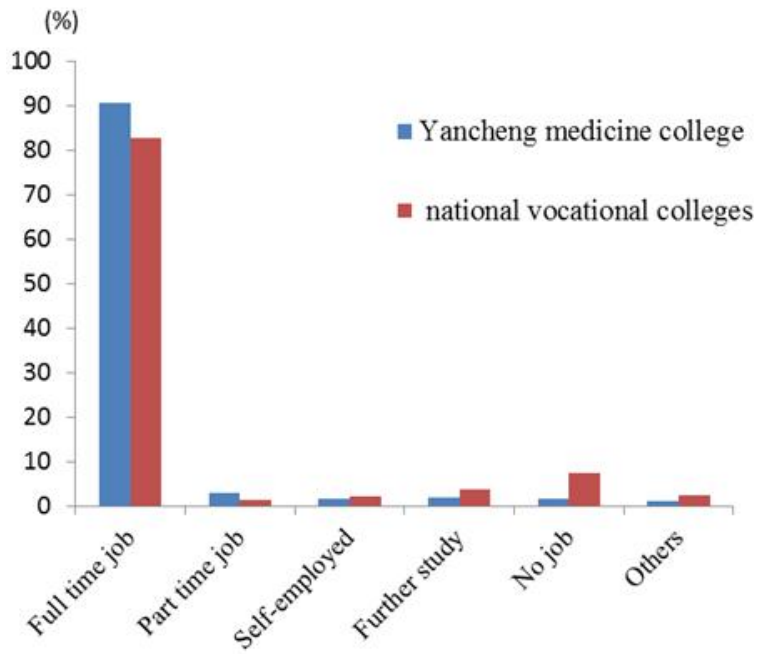

Figure 1. Distribution of the Graduates after Half a Year

\section{B. Overall Finding}

The results of the overall employment index were listed in Table 1, which contained employment rate, average monthly income, working ability and job satisfaction. Based on the data, the employment competitiveness index, the comprehensive evaluation of the employability of graduates, was calculated. The major of nursing (Midwifery) have the highest employment competitiveness index $(99.3 \%)$, the major with the lowest employment competitiveness index is Pharmacy (82.3\%).

The average employment status of satisfaction for our college is $42 \%$, a little lower than the employment status of national higher vocational colleges $(44 \%)$. The graduate with nursing (Midwifery) major were the most satisfied with their job (59\%), the graduate from pharmacy were the lowest satisfied with their job (36\%).

\section{The Reasons for the Selection of Job}

There are $92 \%$ graduates took the job which were relative with the major they learnt in college. The survey for the graduates who didn't took the major-relative work showed that the main reason was correlated with the number of job recruitment $(34 \%)$ and expectation for the career $(28 \%)$. All the reasons were showed in Figure 2.

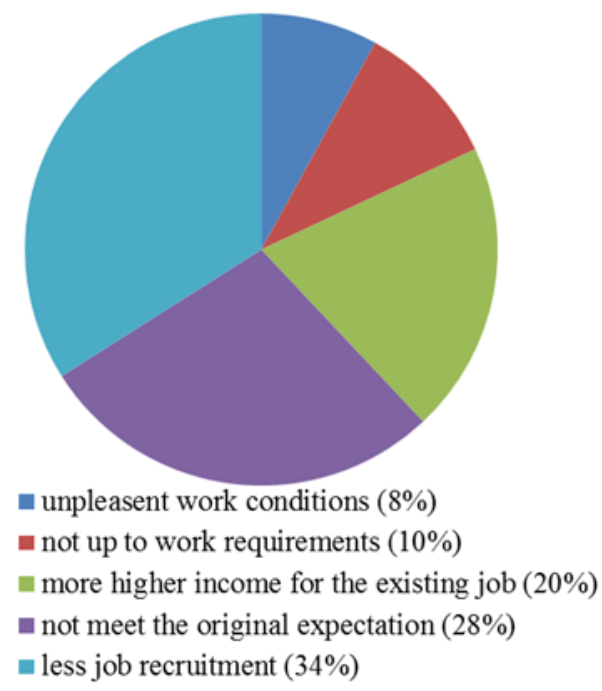

Figure 2. the Reasons for the Selection of Job not Related to his Major

\section{The Aspects Need to be Improved Suggested by the Graduate}

In the survey, the graduates also give the assessment and suggestions for the training process in college, the main results were presented in Figure 3. It is considered that the weakest point in teaching is not enough expert skill practice (33\%), the second is unable to mobilize the students' interest in learning (32\%). Other comments such as outmoded content in teaching, not enough interaction in 
class, unreasonable assessment method were also mentioned. The comments on teachers about professional ability and businesslike attitude of teacher were relatively great. The information will accelerate the improvement of teaching mode, and teaching methods adjust teaching content and how to test.

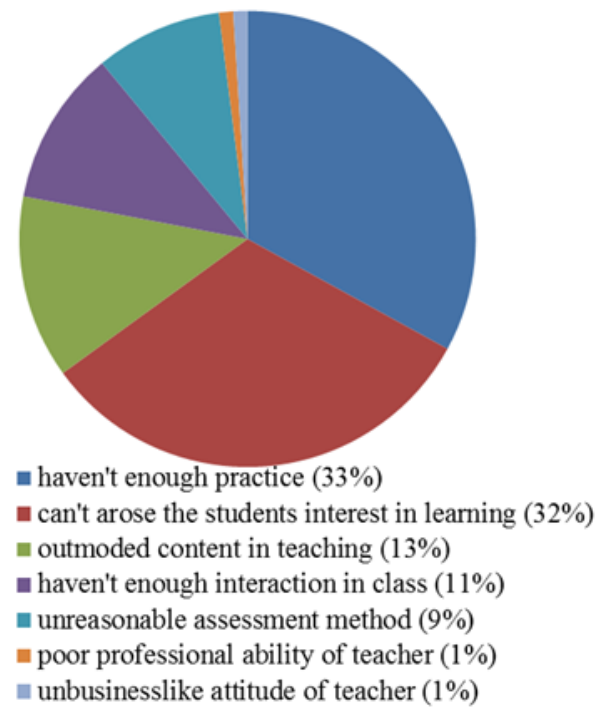

Figure 3. the Aspects Need to be Improved Suggested by the Graduate

\section{E. The Analysis of College Clubs Activities}

The college clubs were a part of campus life, the effects of these activities were also investigated. There are plenty of clubs in our college, and the participation rate of the graduate of 2014 class was $74 \%$. There are $34 \%$ students who participated in art and culture clubs, and $83 \%$ students among them were satisfied with the clubs. Only $11 \%$ students took social practice, and $96 \%$ students among them were satisfied with the activities.

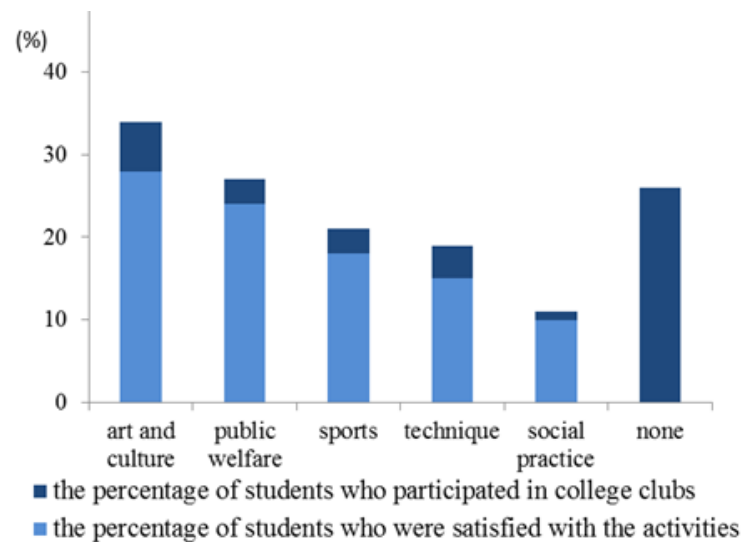

Figure 4. Analysis of Participation in College club activities

The differences of satisfaction with their recent job between the graduates who participate in college clubs and who have no college clubs activity were investigated. The results were presented in Figure 5. The graduates who were in sports clubs were more satisfied with their recent work than the graduates who didn't attend sport activities. The difference of work satisfaction between participate public welfare clubs and not was the smallest.

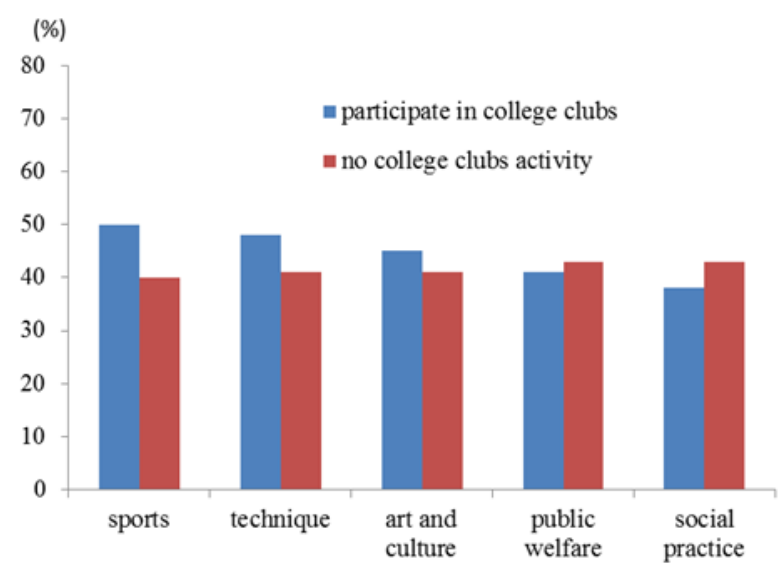

Figure 5. the Satisfaction for their Job of TWO Different Graduate Groups

The effect of participating in college clubs on working ability was analyzed and showed in Figure 6 . The satisfaction for their working ability of graduates who participated in college clubs was all not less than that of no clubs activity. The satisfaction degree of graduates who took social practice was the highest $(96 \%)$ and the difference between the social practice participating groups not was the largest.

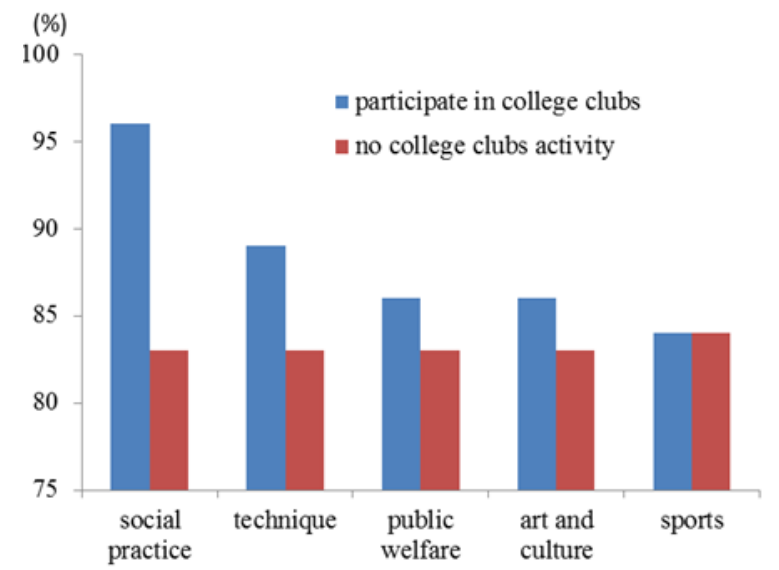

Figure 6. Satisfaction for their Working ability of two Different Groups

\section{DISCUSSION AND CONCLUSIONS}

From the overall results of the survey, the employment of graduates in our college is a little better than the average level of national colleges [6]. This may be due to our career planning education and college clubs encourage policy. By attending our programs of visiting pharmacy company, communicating with the doctors and nurses in hospital, attending lectures from many medical experts, the students were influenced by the workplace culture and come to the identity sense early [7].

There is a need to pay attention to the index of monthly income. Theses job focus on nursing related work, for the characteristics of the job in our country, the initial salary is relatively low. The employment rate and professional association degree are high in our college, it shows most graduate could find job and use what they learnt in college.

The high percentage of medical employment rate showed the demand for medical talents in China [8]. Health care industry must have a bright future in China [9]. Medical vocational education should fully use the 
advantage of the health care industry and partner with it. For the world of wellness is becoming fiercely competitive [10], more effort should be taken to strength the building of teaching quality monitoring system and improve the quality of qualified personnel.

\section{ACKNOWLEDGMENT}

This study is supported by Yancheng Medicine College Student Management Project, under project No. 20154210.

\section{REFERENCES}

[1] Y. Chen, Y. Tang, "Discussion on Construction and Development of Local Higher Vocational Colleges' Teaching Supervision," Physics Procedia, vol.33, 2012, pp.1149-1154.

[2] Alison Fuller, "Vocational Education," International Encyclopedia of the Social \& Behavioral Sciences (Second Edition), 2015, pp. 232-238.

[3] Jin Yang, "The tough choice in the Chinese education policy," International Journal of Educational Development, vol.18, July 1998, pp.289-304.

[4] R. Maclean, M. Pavlova, "Planning and Policy Development for Technical Vocational Education and Training Systems,"
International Encyclopedia of Education (Third Edition), 2010, pp.469-475.

[5] I. M. Andersson, K. Gunnarsson, G. Rosèn, "Role of Headmasters, Teachers, and Supervisors in Knowledge Transfer about Occupational Health and Safety to Pupils in Vocational Education," Safety and Health at Work, In Press, Available online 20 August 2015.

[6] H.M. Yi, L.X. Zhang, Y.Z. Yao, A. Wang, Y. Ma, Y.J. Shi, J. Chu, P. Loyalka, S. Rozelle, "Exploring the dropout rates and causes of dropout in upper-secondary technical and vocational education and training (TVET) schools in China," International Journal of Educational Development, vol.42, May 2015, pp.115-123.

[7] Simon McGrath, "Vocational education and training for development: A policy in need of a theory," International Journal of Educational Development, Vol. 32, Sep 2012, pp. 623-631.

[8] F.C. Cai, H.F. Xi, "Study weariness of vocational college students and reform of the teaching mode in Nursing Basic Technology course" Chinese Nursing Research, Vol 2, Mar 2015,pp. 6-8

[9] Z.J. Hou, S. Alvin Leung, "Vocational aspirations of Chinese high school students and their parents' expectations," Journal of Vocational Behavior, vol. 79, Oct 2011, pp. 349-360.

[10] R. Höghielm, "Adult Basic Education: A Challenge for Vocational Based Learning," International Encyclopedia of Education (Third Edition), 2010, pp. 102-106. 